\title{
ACTIVE GROUPS OF BICYCLOMYCIN AND THE REACTION WITH THIOLS
}

\author{
Akira Someya, Manabu Iseki* and Nobuo Tanaka \\ Institute of Applied Microbiology, University of Tokyo, Tokyo \\ *Research Laboratories, Fujisawa Pharmaceutical Co., Ltd., Osaka, Japan
}

(Received for publication December 15, 1978)

\begin{abstract}
The binding of $\left[{ }^{14} \mathrm{C}\right]$ bicyclomycin to whole cells of $E$. coli and to the inner membrane proteins was inhibited by dithiothreitol and 2-mercaptoethanol. The reactivity of the drug wit 1 the sulfhydryl group was further studied, using methanethiol as a model compound. The kinetics revealed that the reaction was of pseudo-first-order in excess of thiolate anion. Analysis with gas chromatography-mass spectrometry showed that the main product was an adcluct of thiol with bicyclomycin in an equal molar ratio. The structure of the adduct was determined by ${ }^{1} \mathrm{H}$-NMR spectrometry, showing that thiolate attacked the olefinic double bond of the antibiotic. 3'-Acyl derivatives of bicyclomycin did not significantly affect the binding of $\left[{ }^{14} \mathrm{C}\right]$ bicyclomycin to inner membrane proteins of E. coli. The results suggested that 4,5-double bond hydrocarbons and 3'-hydroxy group of bicyclomycin participate in the binding to $E$. coli inner membrane proteins, which are presumably the receptors of the antibiotic. The olefinic double bond seems to be the active center of bicyclomycin, reacting with the sulfhydryl group of the receptor protein, although the whole molecule is needed for the activity.
\end{abstract}

Bicyclomycin, produced by Streptomyces sapporoensis, is a cyclic peptide antibiotic of an unique structure, and inhibits growth of some Gram-negative organisms ${ }^{1 \sim 5}$ (Fig. 1). The mechanism of action of the antibiotic has been investigated with Escherichia coli $^{6,7)}$. Bicyclomycin induces multinucleate and aseptate filaments, and block:; biosynthesis of lipoprotein bound to peptidoglycan. The drug tinds to the inner membrane proteins, which are different from penicillin-binding proteins. The function of bicyclomycinbinding proteins remains to be determined.

We have studied the nature of binding of bicyclomycin to E. coli membrane proteins and the reactivity with thiols; and the results are presented in this publication.

Fig. 1: Structure of bicyclomycin.

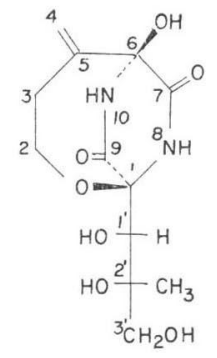

\section{Materials and Methods}

$\left[{ }^{14} \mathrm{C}\right]$ Bicyclomycin $\left(8.0 \mathrm{Ci} /\right.$ mole), prepared by the method described previously ${ }^{7)}$; and acyl derivatives of bicyclomycin, butyrate and benzoate, were generously given by Fujisawa Pharmaceutical Co., Ltd., Osaka. Sodium methanethiolate and 2-mercaptoethanol were purchased from Tokyo Kasei Kogyo Co., Ltd., and dithiothreitol from Seikagaku Kogyo Co., Ltd., Tokyo.

The binding of $\left[{ }^{14} \mathrm{C}\right]$ bicyclomycin to membrane proteins of E. coli JE5506 was carried out as described previously ${ }^{\eta)}$, except that 2 -mercaptoethanol was not used in membrane preparation. The procedure of $\left[{ }^{14} \mathrm{C}\right]$ bicyclomycin binding to the whole cells followed the method of ONISHI et al. ${ }^{8)}$ Slab gel electrophoresis and detection of $\left[{ }^{14} \mathrm{C}\right]$ bicyclomycin-binding proteins were performed by the technique of SPRATT ${ }^{9}$, except that the inner membrane was solubilized by $2 \%(\mathrm{w} / \mathrm{v})$ sodium lauroylsarcosinate. Two kinds of SDS polyacrylamide slab gel systems were employed: system 1 contained $12.5 \%$ (w/v) 
acrylamide and $0.33 \%(\mathrm{w} / \mathrm{v})$ methylene bisacrylamide (LAEMMLI ${ }^{10)}$ ), and system 2 methylene bisacrylamide $(0.068 \%)$ and acrylamide $(10 \%)$. The exposure period for fluorography was about 9 weeks at $-75^{\circ} \mathrm{C}$.

Thin-layer chromatography (TLC) of bicyclomycin and its thiol adducts was performed on silica gel plates (Wakogel $\mathrm{F}_{254}$ ), using a solvent system of chloroform - methanol (5:1, v/v); and the compounds were detected by staining with iodine vapor. The kinetics of reaction of bicyclomycin with excess methanethiolate were determined by measuring density of iodine-stained spots with a microdensitometer. The main product (Rf 0.4 on TLC) was obtained by reacting $500 \mathrm{mg}$ of bicyclomycin with $2.5 \mathrm{ml}$ of $15 \%(\mathrm{w} / \mathrm{v})$ sodium methanethiolate for 30 minutes at room temperature, and purified by repeated TLC as described above. Gas chromatography-mass spectrometry was carried out with Shimazu GCMS-9000S; and ${ }^{1} \mathrm{H}-\mathrm{NMR}$ spectrometry and spin-spin decoupling study with JNM-4H-100 spectrometer at $100 \mathrm{MHz}$ in $\mathrm{CD}_{3} \mathrm{OD}$, containing trimethyl silane as an internal standard.

\section{Results}

Inhibition of $\left[{ }^{14} \mathrm{C}\right]$ Bicyclomycin Binding to E. coli Whole Cells by Thiols

Dithiothreitol and 2-mercaptoethanol were observed to block the binding of $\left[{ }^{14} \mathrm{C}\right]$ bicyclomycin to the whole cells of E. coli JE5506 (Fig. 2). Complete inhibition of the binding was produced at thiol concentrations higher than $10 \mathrm{~mm}$. The results suggested that the sulfhydryl function of the thiols may compete with that of membrane proteins or other components of E. coli.

Effects of Thiols and Acyl Derivatives of Bicyclomycin on $\left[{ }^{14} \mathrm{C}\right]$ Bicyclomycin Binding to Inner Membrane Proteins of E. coli

The pattern obtained by fluorography of inner membrane proteins treated with $\left[{ }^{14} \mathrm{C}\right]$ bicyclomycin (bicyclomycin-binding proteins, BBPs) was almost identical with, but somewhat different from the one described in the previous report ${ }^{7}$; and additional minor binding proteins (BBPs 8,9 and 10) were observed, using slab gel system 1 (Fig. 3A). The difference was probably due to the procedure of preparing membrane fractions:

Fig. 2. Inhibition of $\left.{ }^{[14} \mathrm{C}\right]$ bicyclomycin binding to E. coli whole cells by thiols.

The cells of E. coli JE5506 (25 mg dry weight/ tube) in $66 \mathrm{~mm} \mathrm{pH} 7.0$ phosphate buffer were incubated with various concentrations of dithiothreitol or 2-mercaptoethanol for 10 minutes at $30^{\circ} \mathrm{C}$, and then with $\left[{ }^{14} \mathrm{C}\right]$ bicyclomycin (final concentration $10 \mu \mathrm{g} / \mathrm{ml}$ ) for 30 minutes at $30^{\circ} \mathrm{C}$. The cells were washed 3 times in the same buffer by centrifugation.

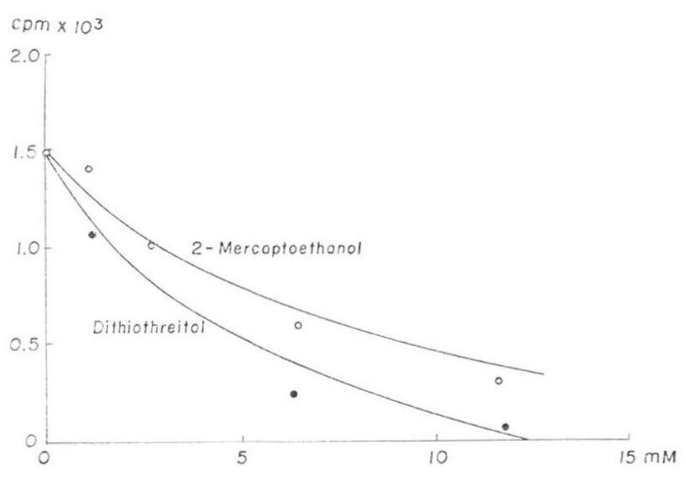
2-mercaptoethanol was employed in the previous experiments $^{7)}$, but not in the current ones. With slab gel system 2, BBPs 2, 3 and 4, which were detected as single proteins in gel system 1, were separated into double bands (Fig. 3B). The binding of $\left[{ }^{14} \mathrm{C}\right]$ bicyclomycin was markedly inhibited by pretreating the cell envelope with dithiothreitol or 2mercaptoethanol (Fig. $3 \mathrm{C}$ and D). On the contrary, the binding pattern was not significantly affected by the pretreatment with acyl derivatives of bicyclomycin: butyrate and benzoate (Fig. 3 $\mathrm{E}$ and $\mathrm{F}$ ).

Reaction of Bicyclomycin with Methanethiol

For the purpose of elucidating the mechanism of reaction of bicyclomycin with the sulfhydryl group, the reaction was studied using methanethiolate as a model compound. As determined by 
Fig. 3. Effects of thiols and acylbicyclomycins on $\left[{ }^{14} \mathrm{C}\right]$ bicyclomycin binding to inner membrane proteins o E. coli.

$\left[{ }^{14} \mathrm{C}\right]$ Bicyclomycin $(250 \mu \mathrm{g} / \mathrm{ml})$ was bound to envelopes of E. coli JE5506 for 30 minutes at $30^{\circ} \mathrm{C}$, and bicyclomycin-binding proteins were fractionated by SDS polyacrylamide gel electrophoresis, using system 1 gel (A). The envelope fractions were preincubated for 10 minutes at $30^{\circ} \mathrm{C}$ with distilled water (B), dithiothreitol $4 \mathrm{mg} / \mathrm{ml}$ (C), 2mercaptoethanol $5 \mathrm{mg} / \mathrm{ml}$ (D), bicyclomycin-3'benzoate $3.2 \mathrm{mg} / \mathrm{ml}$ (E), or bicyclomycin-3'-butyrate (F); then $\left[{ }^{14} \mathrm{C}\right]$ bicyclomycin was added to the mixture and Sarkosyl-soluble proteins were separated by system 2 slab gel electrophoresis.

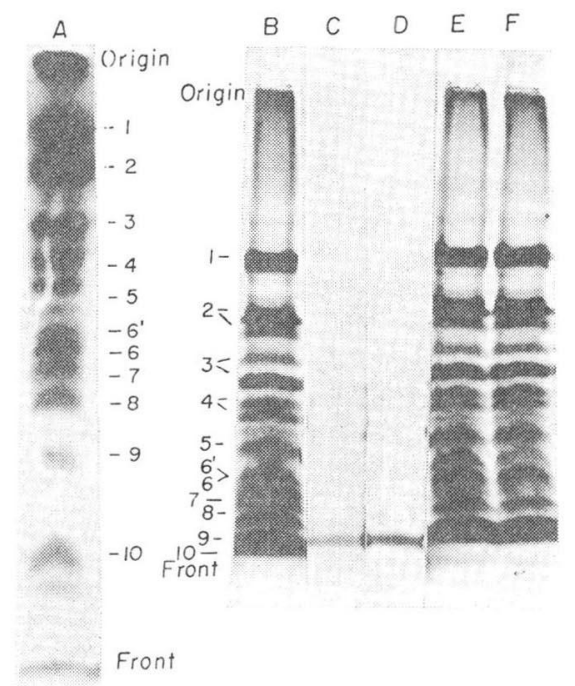

Fig. 4. Thin-layer chromatography (TLC) of reaction products of bicyclomycin and methanethiolate.

The reaction mixture contained: $122 \mathrm{~mm}$ sodium methanethiolate and $6.6 \mathrm{~mm}$ bicyclomycin, $\mathrm{pH}$ $12.5(\mathrm{pH}$ was adjusted with $0.1 \mathrm{~N} \mathrm{HCl}$ ), and was incubated for 30 minutes at $25^{\circ} \mathrm{C}$. The products were separated by TLC, and detected by iodine vapor. Amounts of the products were measured by a microdensitometer.
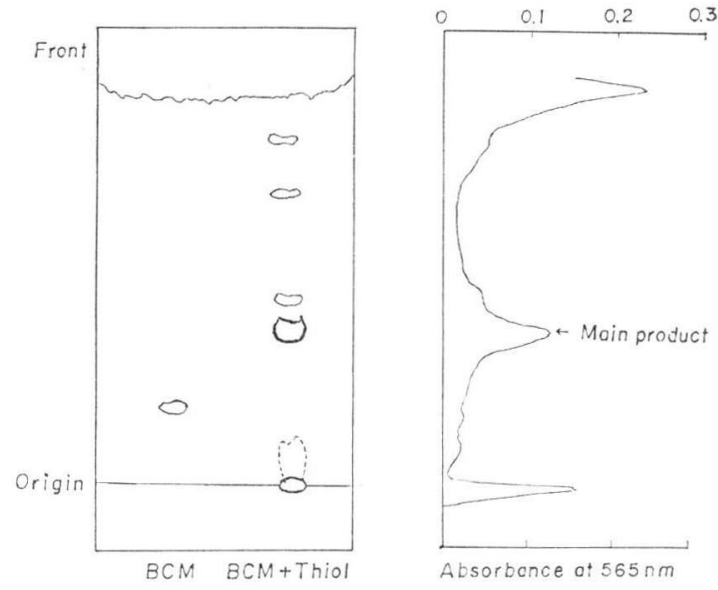

TLC, bicyclomycin ( $\mathrm{Rf} 0.18$ ) rapidly reacted with sodium methanethiolate in $\mathrm{pH} 12.5$ solution at $25^{\circ} \mathrm{C}$, forming a main product of higher mobility (Rf 0.4) and several minor ones (Fig. 4). Bicyclomycin did not significantly decompose under the same conditions. The kinetics of reaction of bicyclomycin and excess methanethiolate were determined, showing that the reaction seemed to be of pseudo-first-order (Fig. 5a). A linear relationship was found between logarithm of the reaction rate constant $\left(\mathrm{k}^{\prime}\right)$ and $\mathrm{pH}($ Fig. 5b). The results suggested that the observed pseudo-first-order rate constants are related to thiolate anion con-

Fig. 5. Kinetics and $\mathrm{pH}$ dependency of reaction of bicyclomycin with excess methanethiolate. The procedures followed those described in the legend of Fig. 3.
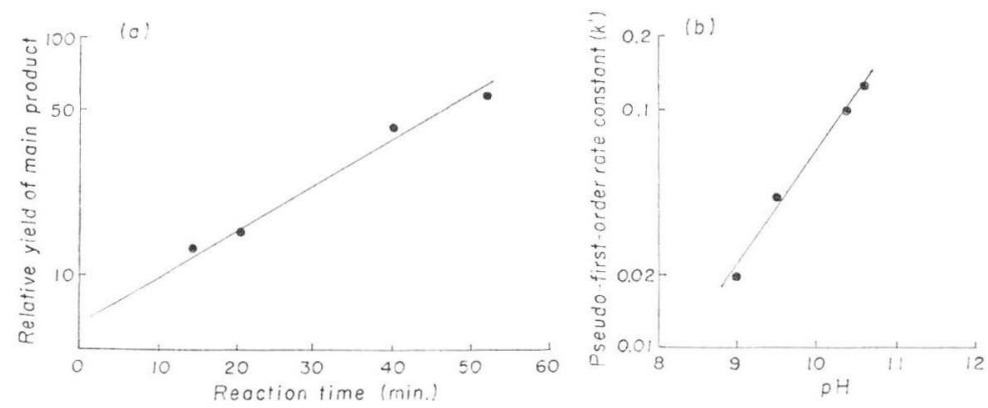
centrations, and thiolate anion directly reacts with bicyclomycin.

Structural Determination of the Main Product of Bicyclomycin-Methanethiol Adducts

The main product (Rf 0.4 on TLC) was purified as described in "Materials and Methods", and was silylated with trimethylsilyl imidazole. The silylated compound was analyzed with gas chromato-

Fig. 6. Mass spectrum of the silylated main adduct of bicyclomycin and methanethiolate.

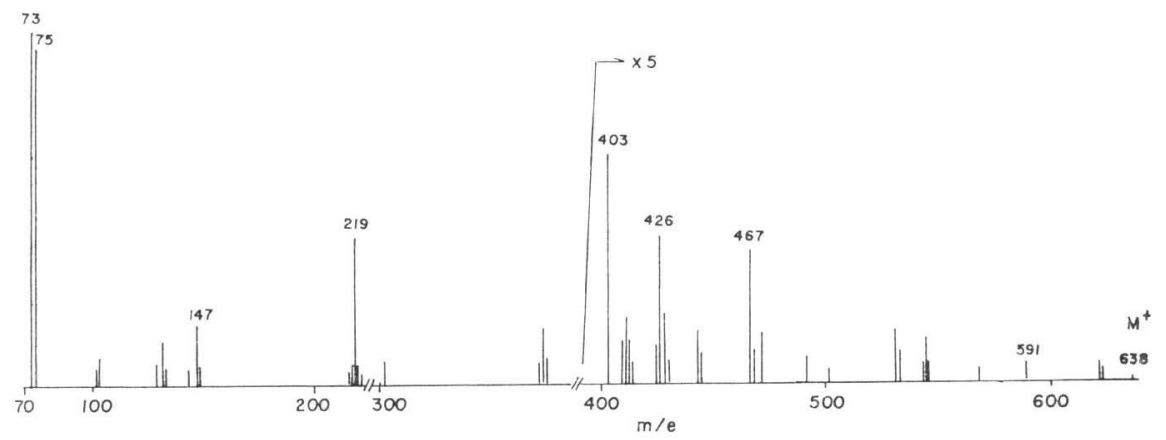

Fig. 7. ${ }^{1} \mathrm{H}$-NMR spectra of bicyclomycin (a) and the methanethiol adduct (b), at $100 \mathrm{MHz}$ in $\mathrm{CD}_{3} \mathrm{OD}$ containing trimethylsilane.
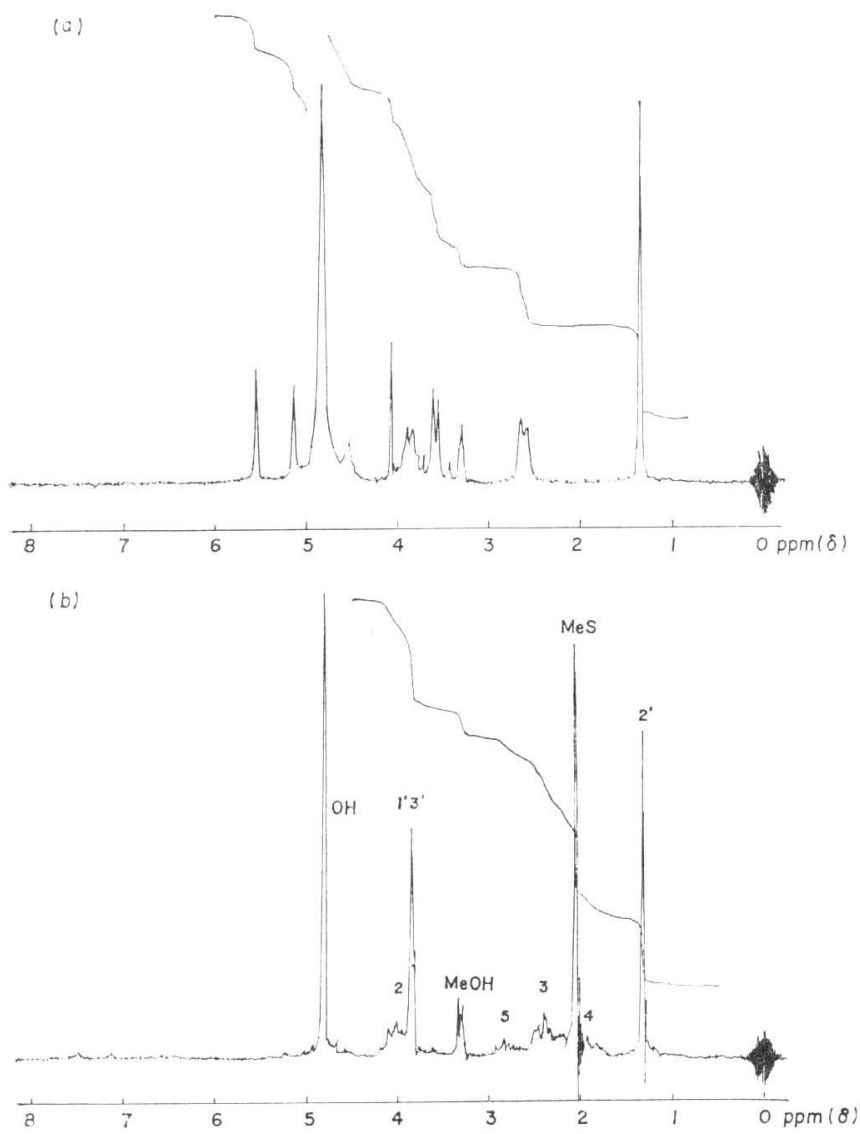

graphy-mass spectrometry. The mass spectrum showed $\mathbf{M}^{+}(m / e$ 638), which coincided with a calculated value for the silylated derivative of one-to-one adduct of methanethiol with bicyclomycin (Fig. 6). It was assumed that 4 silyl groups reacted with 4 hydroxyl groups of bicyclomycin.

The ${ }^{1} \mathrm{H}-\mathrm{NMR}$ spectra of bicyclomycin and the main methanethiol adduct are illustrated in Fig. 7. The assignment of peaks of NMR spectrum of the thiol adduct was

Fig. 8. Structure of a methanethiolbicyclomycin adduct.

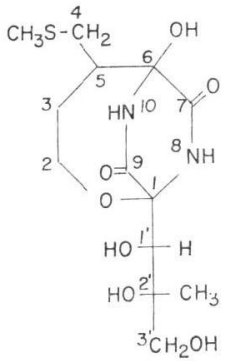

(1)

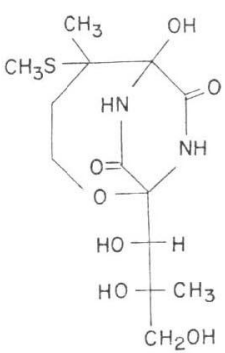

(II) 
made in comparison with those of bicyclomycin and dihydrobicyclomycin ${ }^{2)}$, and by spin-spin decoupling technicue. The signals due to the olefinic protons, which were observed at $\delta 5.14$ (b.s. $1 \mathrm{H}$ ) and 5.54 (b.s. $1 \mathrm{H}$ ) in the spectrum of bicyclomycin, disappeared and a new peak of thiomethyl group appeared in the spectrum of the thiol adduct. These changes indicated that the methanethiol group is bound to $\mathrm{C}_{4}$ or $\mathrm{C}_{5}$ of bicyclomycin (Fig. 8, I or II). Since no signal due to $\mathrm{C}_{5}$-methyl group could be detected in the spectrum, the possibility of structure (II) was excluded. The spectrum of the thiol adduct resembled that of dihydrobicyclomycin ${ }^{2}$, except the thiomethyl group at $\delta 2.06$ and the $\mathrm{C}_{5}$ proton at $\delta 2.83$. $\mathrm{C}_{3}$ - and $\mathrm{C}_{4}$-methylene protons appeared as two two-proton multiplets at $\delta 2.40$ and 1.95. Studies on the spin-spin decoupling for these signals confirmed the above assignment (data are not shown). Thus, all the signals in the NMR spectrum were consistent with structure (I) in Fig. 8.

\section{Discussion}

Bicyclomycin has been observed to induce aseptate and multinucleate filaments in E. coli ${ }^{6}$. The morphological changes resemble those caused by penicillin. However, contrary to penicillin, bicyclomycin did not significantly inhibit cell wall peptidoglycan synthesis in whole cells of $E$. coli ${ }^{6}$. Penicillin-sensitive enzymes: DD-transpeptidase, DD-carboxypeptidase and DD-endopeptidase, are not significantly affected by bicyclomycin (unpublished data). The antibiotic has been found to bind to inner membrane proteins of E. coli, but not to the outer membrane ${ }^{7)}$. Bicyclomycin-binding proteins are definitely distinct from penicillin-binding proteins ${ }^{7)}$. These observations indicate that the mechanism of action of bicyclomycin is similar to, but different from that of penicillins, and remains to be determined.

In the current experiments, the structure-activity relationship of bicyclomycin has been studied. The terminal olefinic double bond is characteristics for the antibiotic, and seems to be important for the activity as well as the $3^{\prime}$-hydroxyl group. No significant antimicrobial activity remains in dihydrobicyclomycin, in which the 4,5-double bond is reduced by catalytic hydrogenation. The results in the present experiments also suggest that the terminal olefinic group reacts with the sulfhydryl groups of the inner membrane proteins and covalent bonds are formed. Thus, the olefinic double bond seems to be the reactive site or functional site of bicyclomycin, although the whole molecule is necessary for the biological activity. The thiol group or thiolate anion may attack the terminal olefinic group of bicyclomycin to form an enolate anion, which may be then protonated.

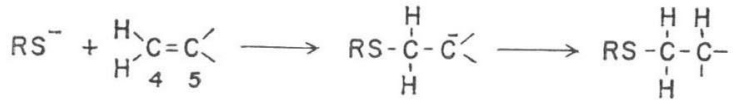

There seems to be another possibility that the reaction may occur by allylic rearrangement.

Many investigators have indicated that the sulfhydryl groups of enzymes play an important role in the catalytic site ( $\mathrm{cf}$. a monograph ${ }^{11)}$ ). Therefore, it is still possibile that bicyclomycin may react with other elements of bacteria and/or interfere with other enzymes. The direct proof of inhibitory effects of bicyclomycin on enzymic functions is expected.

\section{Acknowledgements}

The au:hors express their deep thanks to Prof. S. Okuda, Mr. K. Furuhata, and Mrs. K. Koiso for their kind cooperations in the current experiments. They are also indebted to Dr. HAmAo UMEZAWA for his kind advice and encouragement in the present works.

\section{References}

1) Miyoshi, T.; N. Miyairi, H. Aoki, M. Kohsaka, H. Sasaki \& H. Imanaka: Bicyclomycin, a new antibiotic. I. Taxonomy, isolation and characterization. J. Antibiotics 25: 569 575, 1972 
2) Kamiya, T.; S. Maeno, M. Наshimoto \& Y. Mine: Bicyclomycin, a new antibiotic. II. Structural elucidation and acyl derivatives. J. Antibiotics 25: 576 581, 1972

3) Nishida, M.; Y. Mine, T. Matsubara, S. Goto \& S. Kuwabara: Bicyclomycin, a new antibiotic. III. In vitro and in vivo antimicrobial activity. J. Antibiotics 25: 582 593, 1972

4) Nishida, M.; Y. Mine, T. Matsubara, S. Goto \& S. Kuwabara: Bicyclomycin, a new antibiotic. IV. Absorption, excretion and tissue distribution. J. Antibiotics 25: 594 601, 1972

5) MaAG, H.; J. F. Blount, D. I. Coffen, T. V. Steppe \& F. Wong: Structure, absolute configuration, and total synthesis of an acid-catalyzed rearrangement product of bicyclomycin. J. Am. Chem. Soc. 100: $6786 \sim 6788,1978$

6) Tanaka, N.; M. Iseki, T. Miyoshi, H. Aoki \& H. Imanaka: Mechanism of action of bicyclomycin. J. Antibiotics 29: 155 168, 1976

7) Someya, A.; M. Iseki \& N. TANAKA: Binding of bicyclomycin to inner membrane proteins of $E$. coli. J. Antibiotics 31: 712 718, 1978

8) Onishi, H. R.; S. B. Zimmerman \& E. O. Stapley: Observation on the mode of action of cefoxitin. Ann. N.Y. Acad. Sci. 235: 406 425, 1974

9) Spratt, B. C.: Properties of the penicillin binding proteins of Escherichia coli K12. Eur. J. Biochem. 72: $341 \sim 352,1977$

10) Laemmli, U. K.: Maturation of the head of bacteriophage T4. J. Mol. Biol. 80: 575 599, 1973

11) Jocelyn, P. C.: Biochemistry of the SH group. Academic Press, London and New York, 1972 